Supporting Information

\title{
Wire Melt Electrospun Polymer Nanocomposite Fibers as Radio Frequency Responsive Heaters
}

Kai Morikawa1 , Aniruddh Vashisth¹, Taruna Bansala², Micah J. Green², and Mohammad Naraghi $1^{*}$

${ }^{1}$ Department of Aerospace Engineering, Texas A\&M University, 3409 TAMU, College Station, Texas 77843-3409, United States.

${ }^{2}$ Artie McFerrin Department of Chemical Engineering, Texas A\&M University, 3122 TAMU, College Station, Texas 77843-3122, United States.

*Corresponding author: naraghi@tamu.edu

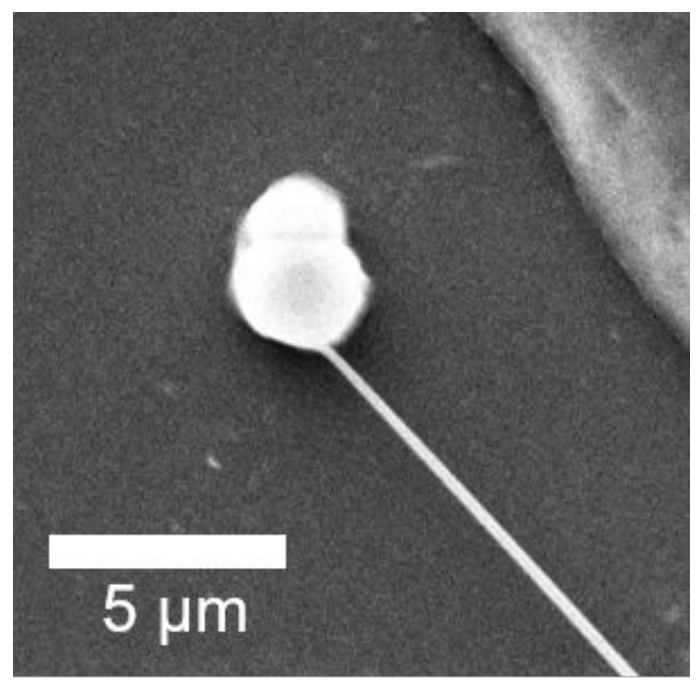

Figure S1: SEM image of $0.5 \mathrm{wt} \% \mathrm{CNT} / \mathrm{PCL}$ melt electrospun fibers showing a bulb with a nanofiber emerging from it 

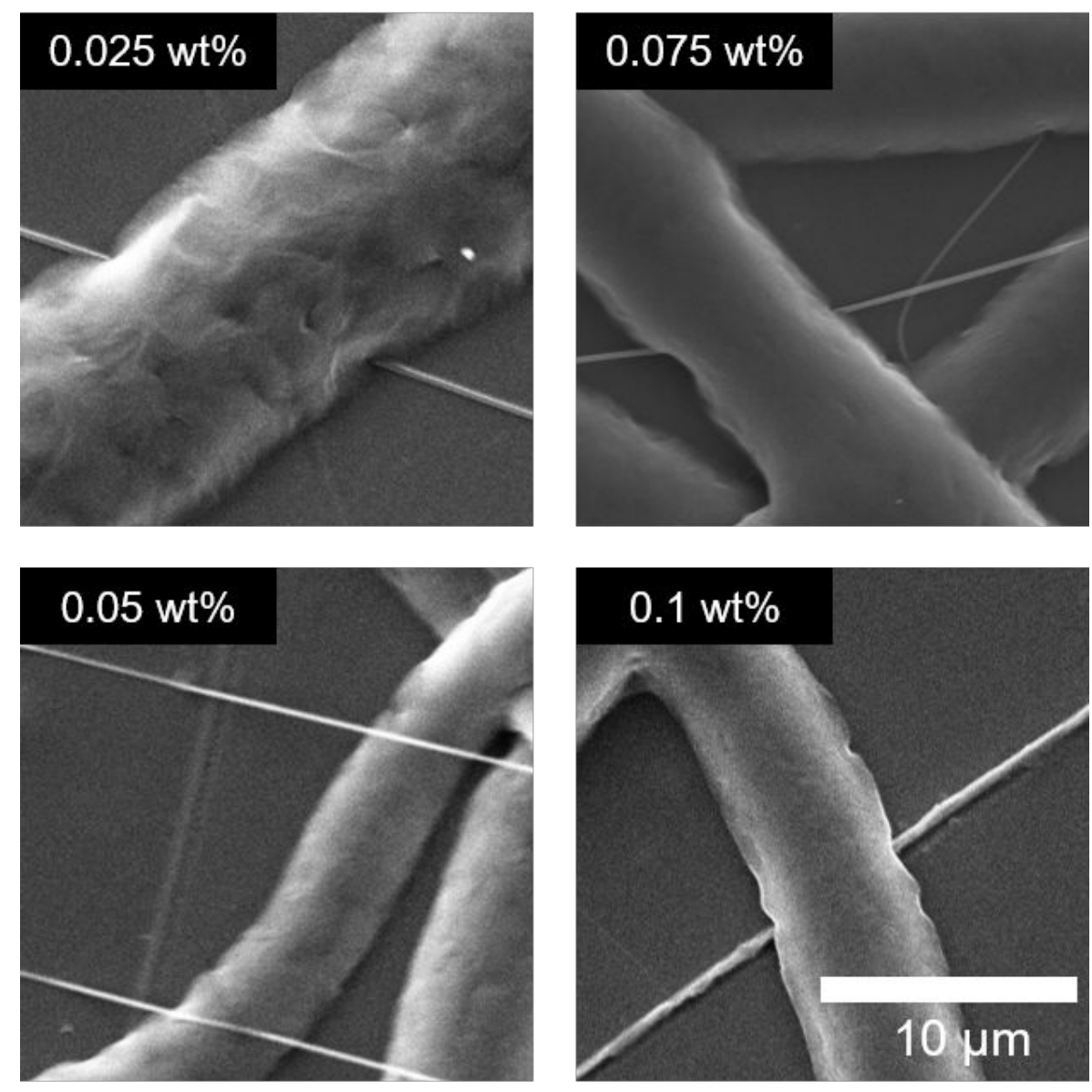

Figure S2: SEM images of CNT/PCL melt electrospun fibers (Scale bar applies to all images) 
(a)
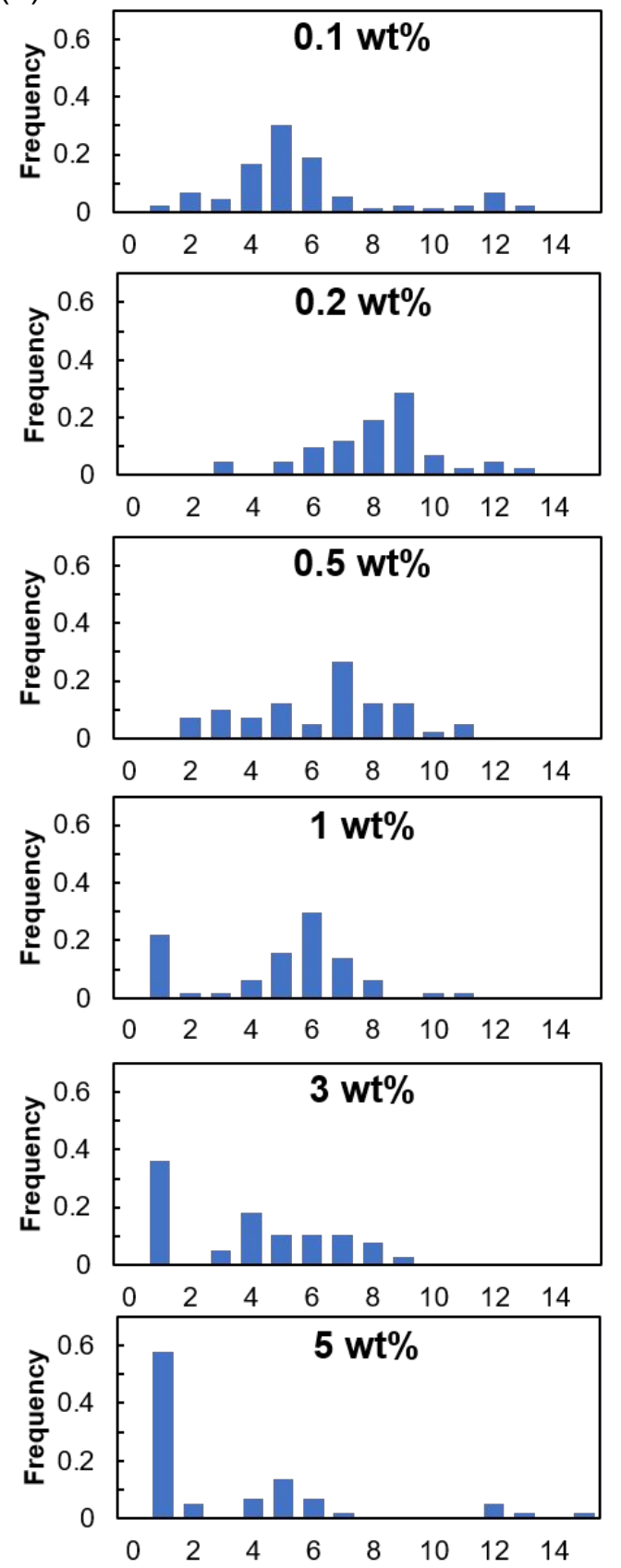

(b)
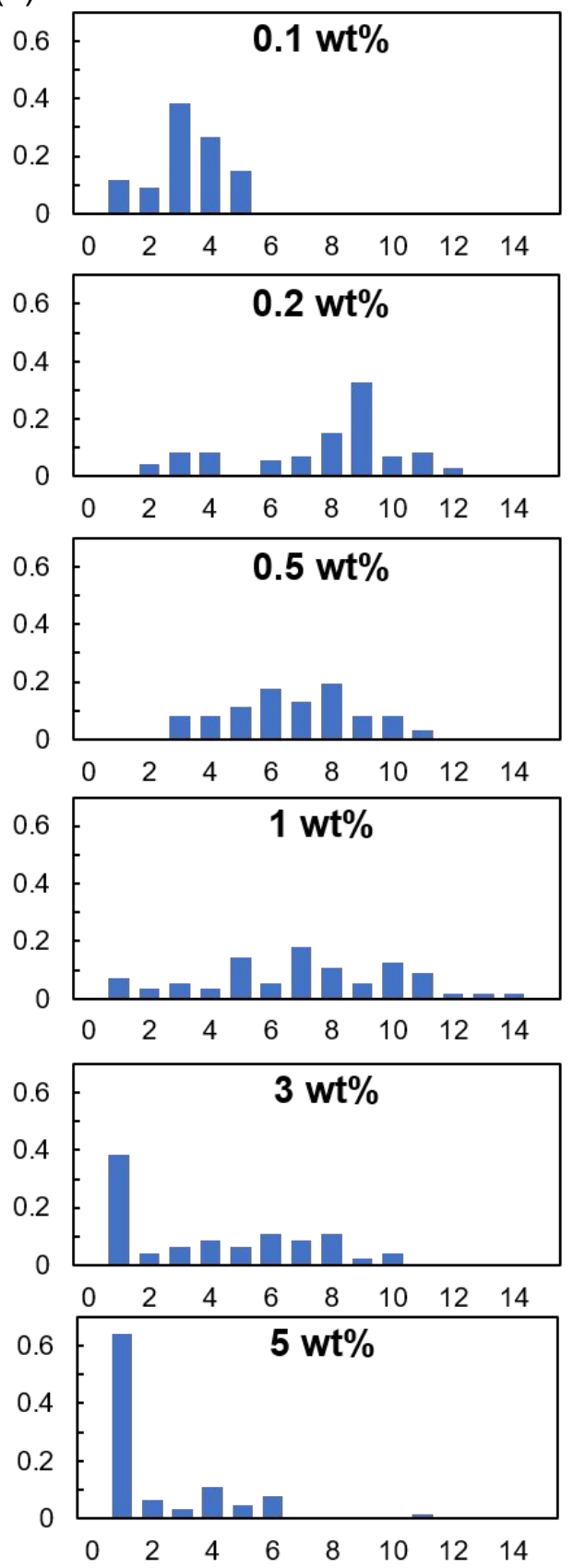

Figure S3: Diameter distribution of melt electrospun fibers for PCL with various CB loadings a) before RF heating and b) after RF heating 


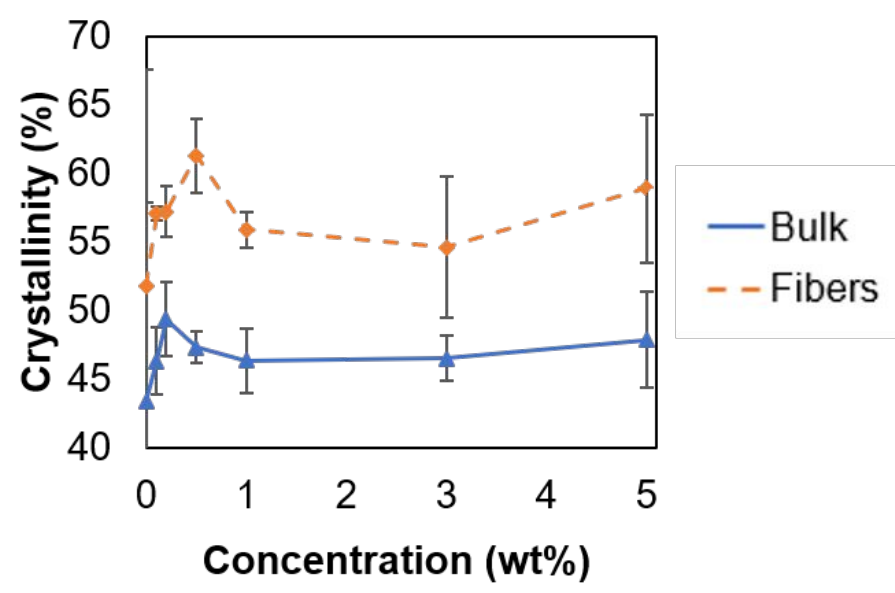

Figure S4: Crystallinity of bulk and melt electrospun fibers of $\mathrm{CB} / \mathrm{PCL}$ for various loadings

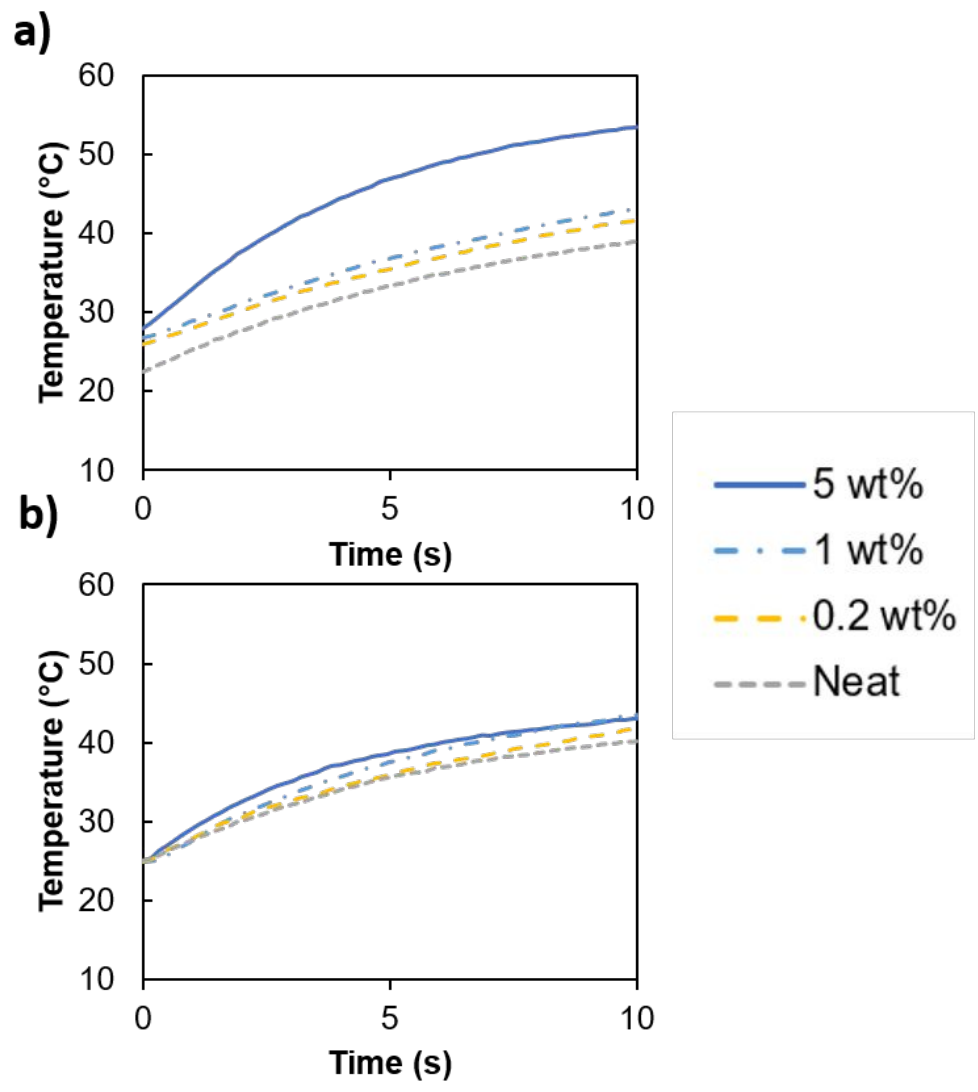

Figure S5: RF heating response of PCL/CB a) bulk and b) fibers. 